\title{
Investigation of the Effect of Fluoroethylene Carbonate Additive on Electrochemical Performance of Sb-Based Anode for Sodium-Ion Batteries
}

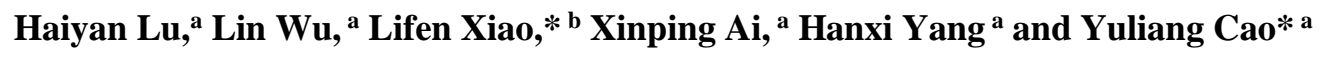 \\ ${ }^{a}$ College of Chemistry and Molecular Sciences, Hubei Key Lab. of Electrochemical Power \\ Sources, Wuhan University, Wuhan 430072, P. R. China. E-mail: ylcao@whu.edu.cn. \\ ${ }^{b}$ College of Chemistry, Central China Normal University, Wuhan 430079, P. R. China. E-mail: \\ lfxiao@mail.ccnu.edu.cn.
}

\begin{abstract}
The electrolyte additive has significant impact on the electrochemical performance of the alloy anode material for sodium-ion batteries. In this work, the surface structure, component and electrochemical performance of the SiC-Sb-C electrode in FEC-free and -containing electrolyte have been investigated by XPS, FTIR, EIS and electrochemical characterizations. The experimental results suggest that FEC actually participates in the formation process of the SEI films on the surface of the electrode. Based on the analysis of the experimental data, a double-layer SEI film mechanism should be suggested and can well explain the mutation of the resistant and potential observed in the charge/discharge curves and EIS. Therefore, the presence of FEC in the electrolyte can minimize the reductive decomposition of the electrolyte and
\end{abstract}


change the morphology, structure and chemical component of the electrode, resulting in the improvement of the electrochemical performance of the electrode.

Keywords: FEC; Electrolyte additive; Sb; Anode; Sodium-ion battery

\section{Introduction}

Sodium-ion batteries (NIBs) have recently attracted wide attention as an alternative to lithium-ion batteries, in particular for large-scale energy storage applications, due to sodium's high abundance, low cost, and very suitable redox potential $\left(\mathrm{E}_{(\mathrm{Na}}^{\mathrm{o}}{ }^{+} / \mathrm{Na}\right)=$ $-2.71 \mathrm{~V}$ versus standard hydrogen electrode; only $0.3 \mathrm{~V}$ above that of lithium) [1-11]. Recently, many publications have appeared in relation to the electrode materials as the sodium insertion host. Major efforts have been devoted to the search for high performance cathode materials, including layer and tunnel structured metal oxides [12-16], open-framework ferrocyanides [17, 18], and phosphates [19]. For the anodes, hard carbon [20-22] materials have been reported to display a specific capacity typically less than $300 \mathrm{mAh} \mathrm{g}^{-1}$ at relatively low current rates, whereas alloy-based materials [23-32] usually provided much higher gravimetric and volumetric specific capacities. Among the various Na-M alloying anode materials, antimony (Sb) appears to be the promising candidate, which can sustain over hundred cycles against $\mathrm{Na}$ a capacity higher than $660 \mathrm{mAh} \mathrm{g}^{-1}[23-25,27,33]$. Additionally, Sb oxides and sulfides have also been investigated due to their potentially high capacity offered by both 
alloying and conversion reaction [34, 35]. However, most of these materials suffer from serious capacity fading during prolonged charge-discharge cycling due to large volume expansion and contraction.

The cycling performance is strongly associated to the quality of the SEI layer formed on the electrode surface, which has been shown to depended on the surface change of the active material during cycling [36]. Some additives are useful in reducing the irreversible capacity loss and improving the cycle life by modifying the surface film composition [37]. Recently, some reports revealed fluoroethylene carbonate (FEC) can improve the cycle life of hard carbon and Sb-based alloy anodes $[26,37]$. Qian et al. reported the $\mathrm{Sb} / \mathrm{C}$ electrode in the FEC-free can only be cycled in the first 50 cycles, whereas the $\mathrm{Sb} / \mathrm{C}$ electrode in the FEC-containing electrolyte can maintain an almost constant capacity of $575 \mathrm{mAh} \mathrm{g}^{-1}$ over 100 cycles, exhibiting a superior cycling stability [26]. However, there have been limited fundamental explorations on the reaction mechanism of FEC in manipulating the SEI formation to improve the cycle life of Sb-based alloy anodes.

Herein, we examined and compared electrochemical properties of SiC-Sb-C electrode in FEC-free and FEC-containing electrolytes. The presence of FEC in the electrolyte finally leads to the formation of a thin, chemically/mechanically stable and structurally compact SEI film. It was found that a potential mutation in the charge/discharge curve can be attributed to the impact of FEC. The results of X-ray photoelectron spectroscopy (XPS), Fourier Transform infrared spectroscopy (FTIR), and Electrochemical Impedance Spectroscopy (EIS) further demonstrate the effect of 
FEC additive on the composition of the SEI layer.

\section{Experimental}

Sb (99.0\% purity, $74 \mu \mathrm{m}$, National Medicine CO., Ltd., Shanghai, China), SiC (99.5\% purity, 40-60 nm), and super P (TIMCAL, Graphite \& Carbon Inc.) were used as received. The preparation of $\mathrm{SiC}-\mathrm{Sb}-\mathrm{C}$ nanocomposites has been reported in our previous work [25]. In a typical experiment, $\mathrm{SiC}$ and $\mathrm{Sb}$ powders with a mass ratio of $\mathrm{SiC}: \mathrm{Sb}=20: 70$ wt $\%$ were ball-milled by high-energy ball milling $(8000 \mathrm{M}$ mixer/mill, SPEX, U.S.A.) of under an argon atmosphere for $8 \mathrm{~h}$. Then the mixture of SiC-Sb was modified with carbon by ball-milling with super $\mathrm{P}$ carbon $(10 \mathrm{wt} \%)$ using a planetary mill (QM-1SP04, Nanjing, China) under an argon atmosphere with the rotation speed of $200 \mathrm{rpm}$ for $6 \mathrm{~h}$ to form $\mathrm{SiC}-\mathrm{Sb}-\mathrm{C}$ (a mass ratio of $\mathrm{SiC}-\mathrm{Sb}-\mathrm{C}=$ 20:70:10 wt\%) nanocomposites. The weight ratio of milling balls to the powder materials was maintained as 20 to 1 .

The crystalline structure of the as-prepared composite was characterized by X-ray diffractometer with $\mathrm{Cu}-\mathrm{K}_{\alpha}$ irradiation (XRD, Shimadzu XRD-6000). The morphological feature of the SiC-Sb-C was characterized by scanning electron microscopy (SEM, Sirion 2000, FEI). X-ray photoelectron spectroscopy measurements were performed using spectrophotometer (XPS, Kratos XSAM 800) with monochromatized $\mathrm{Al} \mathrm{K \alpha}$ radiation $(\mathrm{h} v=1486.6 \mathrm{eV})$. The composition on the surface of the SiC-Sb-C electrode before and after cycling in FEC-free and FEC-containing electrolyte were further characterized by Fourier Transform infrared 
spectroscopy (FTIR, NICOLET, 5700 FTIR).

The alloy anodes were prepared by mixing $70 \mathrm{wt} \%$ SiC-Sb-C composite, $20 \mathrm{wt} \%$ super P, and $10 \mathrm{wt} \%$ Polyacrylic acid (PAA, $25 \mathrm{wt} \%$ ) to form a slurry, which then was applied to copper $(\mathrm{Cu})$ foil and dried at $60{ }^{\circ} \mathrm{C}$ overnight under vacuum. The charge-discharge performances of the electrode were examined by 2016 coin-type cells using the $\mathrm{SiC}-\mathrm{Sb}-\mathrm{C}$ anode as a working electrode and a $\mathrm{Na}$ foil as counter electrode, $1 \mathrm{M} \mathrm{NaClO}_{4}$ dissolved in a mixture of ethylene carbonate (EC) and diethyl carbonate (DEC) (1:1 by volume) with and without $5 \mathrm{wt} \%$ fluoroethylene carbonate (FEC) additive, and the separator was a microporous membrane (Celgard 2400). The $\mathrm{Na}$ foils were home-made by rolling sodium lumps into thin plate, and then cut into circulated disks. The mass loading of the SiC-Sb-C anode is about $2 \mathrm{mg} \mathrm{cm}^{-2}$. All the cells were assembled in a glove box with water/oxygen content lower than $1 \mathrm{ppm}$ and tested at room temperature. The galvanostatic charge-discharge test was conducted on a LAND cycler (Wuhan Kingnuo Electronic Co., China). Cyclic voltammetric measurements were carried out with the coin cells at a scan rate of $0.1 \mathrm{mV} \mathrm{s}^{-1}$ using a CHI 660c electrochemical workstation (ChenHua Instruments Co., China).

\section{Results and discussion}

Morphological and structural features of the $\mathrm{SiC}-\mathrm{Sb}-\mathrm{C}$ composite were characterized by scanning electron microscopy (SEM). As displayed in Fig. 1a, the as-prepared material appears as uneven agglomerates with an average size of several micrometers. Figure $1 \mathrm{~b}$ displays the XRD patterns of the nanosized $\mathrm{SiC}$, metallic $\mathrm{Sb}$, 
and SiC-Sb-C composites. For SiC-Sb-C nanocomposites, the main diffraction reflections can be basically indexed to the cubic $\beta$-SiC (JCPDS no. 75-0254) and hexagonal Sb (JCPDS no. 05-0562) except for some weaker and broader peaks, indicating that no chemical reactions occurred between the $\mathrm{SiC}$ and metallic $\mathrm{Sb}$ during high-energy ball milling. In the $\mathrm{SiC}-\mathrm{Sb}-\mathrm{C}$ nanocomposite, the $\mathrm{SiC}$ provides a stable and inert support for $\mathrm{Sb}$ nanocrystals to buffer the volumetric change of $\mathrm{Sb}$ during charging and discharging. The coating carbon constructs a conducting net to improve electronic conductivity of the material. Such a unique structure enhances the electrochemical performance of $\mathrm{Sb}[25]$.

Figure 2 depicts the initial two discharge/charge profiles of the $\mathrm{SiC}-\mathrm{Sb}-\mathrm{C}$ electrode between 0.01 and $2.0 \mathrm{~V}$ at a current rate of $100 \mathrm{~mA} \mathrm{~g}^{-1}$ in FEC-free and FEC-containing electrolytes. The $\mathrm{SiC}-\mathrm{Sb}-\mathrm{C}$ electrode exhibits the initial reversible capacity of $424 \mathrm{mAh} \mathrm{g}^{-1}$ (Fig. 2a) and $505 \mathrm{mAh} \mathrm{g}^{-1}$ (Fig. 2b) in FEC-free and FEC-containing electrolytes, corresponding coulombic efficiency of about $67.2 \%$ and $72.6 \%$, respectively. The higher reversible capacity of the SiC-Sb-C electrode in FEC-containing electrolyte suggests that the presence of FEC in electrolyte minimizes the reductive decomposition of the electrolyte and modifies the morphological/structural change and chemical composition of the cycled electrode surface passivation layer, so as to reduce the irreversible capacity. In the FEC-containing electrolyte, the charging curve of the first and second cycles almost overlap, indicative of a stable environment of the electrode's structure and surface state during cycling. It is worth noting that a short potential plateaus in the second 
discharge curve for the FEC-containing electrolyte can be clearly observed between 0.5 and $0.2 \mathrm{~V}$, which should be ascribed to the impact of FEC on the surface of the electrode.

Figure 3 compares the cycling performance of $\mathrm{SiC}-\mathrm{Sb}-\mathrm{C}$ electrode at a cycling rate of $100 \mathrm{~mA} \mathrm{~g}^{-1}$ in FEC-free and FEC-containing electrolytes. The reversible capacity of the SiC-Sb-C electrode in the FEC-free electrolyte gradually increases during the initial cycles and then rapidly decreases during prolonged cycling. In comparison, the SiC-Sb-C electrode in the FEC-containing electrolyte can remain almost stable capacity of $492 \mathrm{mAh} \mathrm{g}^{-1}$ over 100 cycles, corresponding to $97.6 \%$ capacity retention of the initial reversible capacity. Even though the coulombic efficiency of the electrode is only $72.6 \%$ during the first cycle, it drastically increases to $99 \%$ after a few cycles and then remains steady during subsequent cycles. The excellent reversibility and capacity retention of the electrode in the FEC-containing electrolyte can be accounted for the effect of FEC additive. It indicates that a compact and stable SEI film should be formed on the surface of the SiC-Sb-C electrode, which can avoid further decomposition of the electrolyte on the surface of the alloy particles at repeated charge and discharge cycles, in good agreement with those reported in the previous literatures [38].

Figure $4 \mathrm{a}$ displays the cyclic voltammograms $(\mathrm{CVs})$ of the electrode in the FEC-free electrolyte. During the first negative scan, the reductive peak at about $0.6 \mathrm{~V}$ is due to the formation of solid electrolyte interface (SEI), which is responsible for the irreversible capacity during the first cycle [25]. One sharp and strong reductive peak 
appears around $0.24 \mathrm{~V}$, which presents at same potential again, corresponding to $\mathrm{Na}$ alloying reaction of $\mathrm{Sb}$ for the formation $\mathrm{Na}_{3} \mathrm{Sb}$ alloy [28]. In the reversed positive scan, a peak observed at $0.91 \mathrm{~V}$ indicates the dealloying reaction of $\mathrm{Sb}$. From $\mathrm{CV}$ curves, only a pair of redox peaks is detected, which differs from some observations (two pairs of redox peaks) in the previous literatures, attributed to two-step alloying/dealloying reaction of $\mathrm{Sb}$ with $\mathrm{Na}[24,25]$. It can be possibly explained that the two-step redox peak overlaps and merges as one broad peak due to the presence of electrochemical polarization to a certain extent. In the subsequent scans, the redox peak currents display a declining trend, implying poor structural stability with cycling. As shown in Fig. 4b, the SiC-Sb-C electrode in FEC-containing electrolyte displays similar CV curves. Only a small difference is observed that the potential of the irreversible reductive peak at first scan slightly shifts to lower value $(0.5 \mathrm{~V})$ compared with that $(0.6 \mathrm{~V})$ in FEC-free electrolyte (Fig. 4a), which might be ascribed to the effect of the introduction of FEC. Some detail discussions are given below. After the first scan, the CV profiles of the electrode almost overlap for the following continuous scans, indicating stable alloying/dealloying reaction and high reversibility of the electrode in the FEC-containing electrolyte. The results imply that FEC additive can form tight and stable SEI film to alleviate the further decomposition of the electrolyte, modify the surface chemistry of the cycled electrodes and suppress the unfavorable side reactions between the electrode and electrolyte.

In order to investigate the effect of FEC additive on the electrochemical performance of Sb-based anode, XPS measurement was carried out to determine the 
difference of the surface characteristics of the SiC-Sb-C electrode in FEC-free and -containing electrolytes. C 1s, F 1s and Sb 3d XPS core peaks of SiC-Sb-C electrode before and after cycling in the FEC-free and FEC-containing electrolytes are presented in Fig. 5. In the FEC-free electrolyte (Fig. 5a), the C 1s spectra of the cycled electrode have the most intense peaks at $285-286 \mathrm{eV}$ and $288-290 \mathrm{eV}$, which corresponds to the hydrocarbon, alkyl carbon and alkoxy species. [39] Compared with the uncycled electrode, the peaks located in this binding energy range in both FEC-free and -containing electrolyte are shifted slightly to higher binding energy, which may be induced by the presence of more alkyl carbon species due to the formation of SEI film after cycling. The C 1s spectra in the FEC-free and -containing electrolyte do not show any difference, suggesting that whether the FEC presents or not in the electrolyte, there is no obvious impact on the chemical environment of $\mathrm{C}$, or the SEI film contributed by $\mathrm{F}$ is mainly near to the surface of the electrode while the out-layer SEI film mostly results from the decomposition of the electrolyte. As shown in Fig. 5b, The electrode in the FEC-containing electrolyte exhibits a pronounced $\mathrm{F}$ peak at around $684 \mathrm{eV}$, corresponding to $\mathrm{NaF}$ and some organic fluorides in the case of FEC presence agreed with that in the literature [36]. This result further indicates that FEC additive have decomposed on the surface of the electrode and contributed to the formation of SEI. Sb $3 \mathrm{~d}_{3 / 2}$ and $\mathrm{Sb} 3 \mathrm{~d}_{5 / 2}$ peaks of the $\mathrm{SiC}-\mathrm{Sb}$-C electrode before and after cycling can also be observed. As shown in Fig. $5 \mathrm{c}$, the peaks of $\mathrm{Sb} 3 \mathrm{~d}_{3 / 2}$ around $394 \mathrm{eV}$ and $\mathrm{Sb} 3 \mathrm{~d}_{5 / 2}$ around $531 \mathrm{eV}$ of the $\mathrm{SiC}-\mathrm{Sb}-\mathrm{C}$ electrode before cycling actually correspond to the signal of antimony oxides, while a shoulder peak at higher 
binding energy than $\mathrm{Sb} 3 \mathrm{~d}_{5 / 2}$ represents the oxygen-containing species on the surface of $\mathrm{Sb}$ electrode [40]. This is because the surface of the metal $\mathrm{Sb}$ does not avoid the presence of an oxide film. After cycling, the $\mathrm{Sb} 3 \mathrm{~d}_{5 / 2}$ peak in FEC-free electrolyte keeps same position while shifts slightly to higher binding energy in FEC-containing electrolyte. This implies that F element might enter the oxide layer on the surface of $\mathrm{Sb}$, leading to the $\mathrm{Sb} 3 \mathrm{~d}_{5 / 2}$ peak shifts to higher position due to higher binding energy for F-Sb bond than O-Sb bond. These results demonstrate the FEC joins into the SEI film and changes the surface structure and chemical environment of SEI film, which would further affect the electrochemical performance of the electrode.

SiC-Sb-C electrode after cycling in the FEC-free and FEC-containing electrolyte were further characterized by FTIR, as displayed in Fig. 5d. The FTIR spectra of the electrode after cycling verify the presence of some alkyl carbon and alkoxy species. The peaks at about $875.86 \mathrm{~cm}^{-1}$ and $1653.91 \mathrm{~cm}^{-1}$ are assigned to $\mathrm{Na}_{2} \mathrm{CO}_{3}$. A small peak at about $1561.90 \mathrm{~cm}^{-1}$ can be attributed to $\mathrm{ROCO}_{2} \mathrm{Na}$. These species are major components of the SEI films. In comparison, the signals of the SiC-Sb-C electrode in the FEC-containing electrolyte are more intensive than that in the FEC-free electrolyte, indicating a stronger and more complicated reaction on the surface of the electrode due to the presence of FEC. In addition, the position of the peaks appears blue-shift in the FEC-containing electrolyte due to stronger bond energy of -F group.

To further verify the difference of the discharge curves during $0.5-0.2 \mathrm{~V}$ between both electrodes due to the presence of FEC (Fig. 2b) and better understand the effect of FEC on the drastically improved electrochemical performance of the SiC-Sb-C 
electrode, electrochemical impedance spectroscopic (EIS) analysis of the SiC-Sb-C electrode in FEC-free and FEC-containing electrolyte were conducted at the $2^{\text {nd }}$ cycle when discharging to $0.5 \mathrm{~V}$ and $0.2 \mathrm{~V}$. As shown in Fig. 6. The SiC-Sb-C electrodes in both electrolytes possess similar electrochemical impedance spectra: two depressed semicircles and inclined line. In general, the semicircle is attributed to the resistance of SEI film $\left(\mathrm{R}_{\mathrm{SEI}}\right)$ and the charge-transfer resistance $\left(\mathrm{R}_{\mathrm{ct}}\right)$ in the high and low frequency range, while the inclined line corresponds to sodium-ion diffusion within the bulk of the electrode material. The kinetic differences of $\mathrm{SiC}-\mathrm{Sb}-\mathrm{C}$ electrode in FEC-free and FEC-containing electrolyte can be investigated by modeling the electrochemical impedance spectra based on an equivalent series resistance circuit (Fig. 6c). The fitted impedance parameters are listed in Table 1. It can be seen that the $\mathrm{SiC}-\mathrm{Sb}-\mathrm{C}$ electrode in FEC-free electrolyte exhibits a drastic increase (more than ten times) no matter what the values of $\mathrm{R}_{\mathrm{SEI}}(66$ to $664.4 \Omega)$ and $\mathrm{R}_{\mathrm{ct}}(61.1$ to $729.5 \Omega$ ) from the initial discharge state $(2.0 \mathrm{~V})$ to $0.5 \mathrm{~V}$, while only a small increase for the values of $\mathrm{R}_{\mathrm{SEI}}(21.8$ to $48.4 \Omega)$ and $\mathrm{R}_{\mathrm{ct}}(160.5$ to $190 \Omega$ ) in FEC-containing electrolyte. This obviously indicates that before discharging to $0.5 \mathrm{~V}$, the decomposition of the electrolyte apparently occurs in FEC-free electrolyte, leading to high electrochemical impedance. However, in FEC-containing electrolyte, FEC is capable to decompose earlier than EC and DEC to firstly form a tight and thin SEI film, which has low electrochemical impedance. When discharging from 0.5 to $0.2 \mathrm{~V}$, it is found that the values of $R_{\text {SEI }}$ and $R_{c t}$ in FEC-free electrolyte remains stable while a drastic increase (about ten times) for the values of $\mathrm{R}_{\mathrm{SEI}}$ and $\mathrm{R}_{\mathrm{ct}}$ in FEC-containing electrolyte. The 
large impedance change would cause large potential polarization, resulting from a potential step in the discharge curve. This phenomenon is in good agreement with the observation from the discharge curve (Fig. 2b). The increase of the impedance of the electrode discharged to $0.2 \mathrm{~V}$ in FEC-containing electrolyte suggests that though FEC can decompose in advance to form the thin SEI film with low resistance, the electrolyte can still decompose in lower potential region to form second-layer SEI film. The double-layer SEI film can also explain why the $\mathrm{Sb} 3 \mathrm{~d}_{5 / 2}$ has higher binding energy in FEC-containing electrolyte observed in XPS (Fig. 5c). Additionally, though the FEC-containing electrolyte can continue decomposing below $0.5 \mathrm{~V}$, the resistance value $(495.6 \Omega)$ of the SEI film is lower than that $(655.1 \Omega)$ in FEC-free electrolyte, indicating that the first-layer SEI film formed by FEC can reduce the total resistance of the SEI film compared with the FEC-free electrolyte. This should be a cause of the improvement of the electrochemical performance by using FEC additive.

According to the above discussion on the CV, charge/discharge, XPS and EIS measurements, the forming mechanism of SEI film of the Sb-based anode in FEC-containing electrolyte should be described as double-layer structure. Figure 7 illustrates the structural scheme of the film-forming mechanism of the SiC-Sb-C electrode in the FEC-free and -containing electrolyte. In FEC-free electrolyte, the carbonate solvents (EC and DEC) gradually decompose on the surface of the $\mathrm{SiC}-\mathrm{Sb}-\mathrm{C}$ particles with discharging to form SEI film. The component of the SEI film should consist of a number of sodium salts, such as $\mathrm{Na}_{2} \mathrm{CO}_{3}, \mathrm{ROCO}_{2} \mathrm{Na}$, $\mathrm{RONa}$ ( $\mathrm{R}$ : alkyl groups), etc. [36]. However, the precipitation layer forming from these salts is 
normally loose, leading to a thick SEI film (Fig. 7a). In FEC-containing electrolyte, FEC firstly decomposes on the surface of the particles due to higher reaction activity for FEC compared with EC and DEC. The fluorine-containing salts (such as $\mathrm{NaF}$, F-ROCO ${ }_{2} \mathrm{Na}$, F-RONa, etc.) resulted from the decomposition of FEC can form dense and thin SEI film (Fig. 7b). Though the fluorine-containing film can suppress the decomposition of the EC and DEC to some certain extent, the EC and DEC can still decompose at lower potential $(<0.5 \mathrm{~V})$ with FEC together to form second-layer SEI film (Fig. 7b). The double-layer structure of SEI film can well explain the mutation of the resistance of SEI film (Fig. 6b) and potential in discharge curve (Fig. 2b) between 0.5 and $0.2 \mathrm{~V}$ for the electrode in the FEC electrode. Although the FEC-containing electrolyte can still decompose on the first-layer film formed by FEC, the total impedance of the electrode is lower than that in FEC-free electrolyte in the whole charge/discharge potential region (Fig. 6 and Tab. 1). Therefore, the improved electrochemical performance of the electrode in FEC electrolyte should be attributed to the decomposition on the surface of the electrode and the formation of the double-layer SEI film due to the presence of FEC additive.

\section{Conclusions}

The effect of FEC on the electrochemical performance and surface chemistry of SiC-Sb-C electrode was thoroughly investigated. The enhanced electrolyte performance of $\mathrm{SiC}-\mathrm{Sb}-\mathrm{C}$ in FEC-containing electrolyte can be attributed to the superior properties of the double-layer SEI film formed during electrochemical 
cycling. XPS, FTIR and EIS measurements in FEC-containing solutions demonstrate that FEC actually participates in the formation process of the SEI films on the surface of the electrode. According to the experimental observation, the presence of FEC in the electrolyte first decomposes to form a dense and thin SEI film (first-layer film) and then other solvents further decompose on the first-layer film to form double-layer SEI film in the low potential region. The double-layer structure of SEI film can well explain the mutation of the resistant and potential observed in the charge/discharge curves and EIS, respectively. Therefore, FEC additive minimizes the reductive decomposition of the electrolyte and modifies the morphological/structural change and chemical component of the surface passivation layer of the cycled electrode, thus dramatically reduces the irreversible capacity and improves the cycling performance of the electrode. This work gives a new view to understand the effects of FEC additive on the surface structure and electrochemical performance of the Sb-based electrode.

\section{Acknowledgments}

We thank financial support by the National Key Basic Research Program of China (No. 2015CB251100), National Science Foundation of China (No. 21173160, 21373155, 21273090), Program for New Century Excellent Talents in University NCET-12-0419) and Hubei National Funds for Distinguished Young Scholars (2014CFA038). 


\section{Reference:}

[1] D. Kundu, E. Talaie, V. Duffort, L.F. Nazar, The Emerging Chemistry of Sodium Ion Batteries for Electrochemical Energy Storage, Angew. Chem. Int. Ed., 54 (2015) 3431-3448.

[2] N. Yabuuchi, K. Kubota, M. Dahbi, S. Komaba, Research Development on Sodium-Ion Batteries, Chem. Rev., 114 (2014) 11636-11682.

[3] H. Li, C. Wu, F. Wu, Y. Bai, Sodium Ion Battery: A Promising Energy-storage Candidate for Supporting Renewable Electricity, Acta Chim. Sinica, 72 (2014) 21.

[4] Y. Kim, K.-H. Ha, S.M. Oh, K.T. Lee, High-Capacity Anode Materials for Sodium-Ion Batteries, Chem.-Eur. J., 20 (2014) 11980-11992.

[5] M.S. Islam, C.A.J. Fisher, Lithium and sodium battery cathode materials: computational insights into voltage, diffusion and nanostructural properties, Chem. Soc. Rev., 43 (2014) 185-204.

[6] M.D. Slater, D. Kim, E. Lee, C.S. Johnson, Sodium-Ion Batteries, Adv. Funct. Mater., 23 (2013) 947-958.

[7] H. Pan, Y.-S. Hu, L. Chen, Room-temperature stationary sodium-ion batteries for large-scale electric energy storage, Energy Environ. Sci., 6 (2013) 2338-2360.

[8] V. Palomares, M. Casas-Cabanas, E. Castillo-Martinez, M.H. Han, T. Rojo, Update on Na-based battery materials. A growing research path, Energy Environ. Sci., 6 (2013) 2312-2337.

[9] S.Y. Hong, Y. Kim, Y. Park, A. Choi, N.-S. Choi, K.T. Lee, Charge carriers in rechargeable batteries: Na ions vs. Li ions, Energy Environ. Sci., 6 (2013) 2067-2081. 
[10] V. Palomares, P. Serras, I. Villaluenga, K.B. Hueso, J. Carretero-Gonzalez, T. Rojo, Na-ion batteries, recent advances and present challenges to become low cost energy storage systems, Energy Environ. Sci., 5 (2012) 5884-5901.

[11] S.-W. Kim, D.-H. Seo, X. Ma, G. Ceder, K. Kang, Electrode Materials for Rechargeable Sodium-Ion Batteries: Potential Alternatives to Current Lithium-Ion Batteries, Adv. Energy Mater., 2 (2012) 710-721.

[12] N. Yabuuchi, M. Kajiyama, J. Iwatate, H. Nishikawa, S. Hitomi, R. Okuyama, R. Usui, Y. Yamada, S. Komaba, P2-type $\mathrm{Na}_{x} \mathrm{Fe}_{1 / 2} \mathrm{Mn}_{1 / 2} \mathrm{O}_{2}$ made from earth-abundant elements for rechargeable Na batteries, Nature Mater., 11 (2012) 512-517.

[13] D. Yuan, W. He, F. Pei, F. Wu, Y. Wu, J. Qian, Y. Cao, X. Ai, H. Yang, Synthesis and electrochemical behaviors of layered $\mathrm{Na} 0_{0.67}\left[\mathrm{Mn}_{0.65} \mathrm{Co}_{0.2} \mathrm{Ni}_{0.15}\right] \mathrm{O}_{2}$ microflakes as a stable cathode material for sodium-ion batteries, J. Mater. Chem. A, 1 (2013) 3895-3899.

[14] Y. Cao, L. Xiao, W. Wang, D. Choi, Z. Nie, J. Yu, L.V. Saraf, Z. Yang, J. Liu, Reversible Sodium Ion Insertion in Single Crystalline Manganese Oxide Nanowires with Long Cycle Life, Adv. Mater., 23 (2011) 3155-3160.

[15] D. Yuan, X. Liang, L. Wu, Y. Cao, X. Ai, J. Feng, H. Yang, A Honeycomb-Layered $\mathrm{Na}_{3} \mathrm{Ni}_{2} \mathrm{SbO}_{6}$ : A High-Rate and Cycle-Stable Cathode for Sodium-Ion Batteries, Adv. Mater., 26 (2014) 6301-6306.

[16] N. Yabuuchi, R. Hara, M. Kajiyama, K. Kubota, T. Ishigaki, A. Hoshikawa, S. Komaba, New O2/P2-type Li-Excess Layered Manganese Oxides as Promising Multi-Functional Electrode Materials for Rechargeable Li/Na Batteries, Adv. Energy 
Mater., 4 (2014) 1301453.

[17] J. Qian, M. Zhou, Y. Cao, X. Ai, H. Yang, Nanosized $\mathrm{Na}_{4} \mathrm{Fe}(\mathrm{CN})_{6} / \mathrm{C}$ Composite as a Low-Cost and High-Rate Cathode Material for Sodium-Ion Batteries, Adv. Energy Mater., 2 (2012) 410-414.

[18] Y. Fang, L. Xiao, X. Ai, Y. Cao, H. Yang, Hierarchical Carbon Framework Wrapped $\mathrm{Na}_{3} \mathrm{~V}_{2}\left(\mathrm{PO}_{4}\right)_{3}$ as a Superior High-Rate and Extended Lifespan Cathode for Sodium-Ion Batteries, Adv. Mater., 27 (2015) 5895-5900.

[19] Y. Fang, L. Xiao, J. Qian, X. Ai, H. Yang, Y. Cao, Mesoporous Amorphous $\mathrm{FePO}_{4}$ Nanospheres as High-Performance Cathode Material for Sodium-Ion Batteries, Nano Lett., 14 (2014) 3539-3543.

[20] R. Suresh Babu, M. Pyo, Hard Carbon and Carbon Nanotube Composites for the Improvement of Low-Voltage Performance in Na Ion Batteries, J. Electrochem. Soc., 161 (2014) A1045-A1050.

[21] S. Komaba, W. Murata, T. Ishikawa, N. Yabuuchi, T. Ozeki, T. Nakayama, A. Ogata, K. Gotoh, K. Fujiwara, Electrochemical Na Insertion and Solid Electrolyte Interphase for Hard-Carbon Electrodes and Application to Na-Ion Batteries, Adv. Funct. Mater., 21 (2011) 3859-3867.

[22] Y. Cao, L. Xiao, M.L. Sushko, W. Wang, B. Schwenzer, J. Xiao, Z. Nie, L.V. Saraf, Z. Yang, J. Liu, Sodium Ion Insertion in Hollow Carbon Nanowires for Battery Applications, Nano Lett., 12 (2012) 3783-3787.

[23] L. Wu, H. Lu, L. Xiao, X. Ai, H. Yang, Y. Cao, Electrochemical properties and morphological evolution of pitaya-like Sb@C microspheres as high-performance 
anode for sodium ion batteries, J. Mater. Chem. A, 3 (2015) 5708-5713.

[24] L. Wu, X. Hu, J. Qian, F. Pei, F. Wu, R. Mao, X. Ai, H. Yang, Y. Cao, Sb-C nanofibers with long cycle life as an anode material for high-performance sodium-ion batteries, Energy Environ. Sci., 7 (2014) 323-328.

[25] L. Wu, F. Pei, R. Mao, F. Wu, Y. Wu, J. Qian, Y. Cao, X. Ai, H. Yang, SiC-Sb-C nanocomposites as high-capacity and cycling-stable anode for sodium-ion batteries, Electrochim. Acta, 87 (2013) 41-45.

[26] J. Qian, Y. Chen, L. Wu, Y. Cao, X. Ai, H. Yang, High capacity Na-storage and superior cyclability of nanocomposite $\mathrm{Sb} / \mathrm{C}$ anode for $\mathrm{Na}$-ion batteries, Chem. Commun., 48 (2012) 7070-7072.

[27] A. Darwiche, C. Marino, M.T. Sougrati, B. Fraisse, L. Stievano, L. Monconduit, Better Cycling Performances of Bulk $\mathrm{Sb}$ in Na-Ion Batteries Compared to Li-Ion Systems: An Unexpected Electrochemical Mechanism, J. Am. Chem. Soc., 134 (2012) 20805-20811.

[28] L. Xiao, Y. Cao, J. Xiao, W. Wang, L. Kovarik, Z. Nie, J. Liu, High capacity, reversible alloying reactions in $\mathrm{SnSb} / \mathrm{C}$ nanocomposites for $\mathrm{Na}$-ion battery applications, Chem. Commun., 48 (2012) 3321-3323.

[29] L. Wu, X. Hu, J. Qian, F. Pei, F. Wu, R. Mao, X. Ai, H. Yang, Y. Cao, A Sn-SnS-C nanocomposite as anode host materials for Na-ion batteries, J. Mater. Chem. A, 1 (2013) 7181-7184.

[30] L. Wu, H. Lu, L. Xiao, J. Qian, X. Ai, H. Yang, Y. Cao, A tin(ii) sulfide-carbon anode material based on combined conversion and alloying reactions for sodium-ion 
batteries, J. Mater. Chem. A, 2 (2014) 16424-16428.

[31] B. Qu, C. Ma, G. Ji, C. Xu, J. Xu, Y.S. Meng, T. Wang, J.Y. Lee, Layered

$\mathrm{SnS}_{2}$-Reduced Graphene Oxide Composite - A High-Capacity, High-Rate, and Long-Cycle Life Sodium-Ion Battery Anode Material, Adv. Mater., 26 (2014) 3854-3859.

[32] M. Gu, A. Kushima, Y. Shao, J.-G. Zhang, J. Liu, N.D. Browning, J. Li, C. Wang, Probing the Failure Mechanism of $\mathrm{SnO}_{2}$ Nanowires for Sodium-Ion Batteries, Nano Lett., 13 (2013) 5203-5211.

[33] H.S. Hou, M.J. Jing, Y.C. Yang, Y.R. Zhu, L.B. Fang, W.X. Song, C.C. Pan, X.M. Yang, X.B. Ji, Sodium/Lithium Storage Behavior of Antimony Hollow Nanospheres for Rechargeable Batteries, Acs Appl. Mater. Interfaces, 6 (2014) 16189-16196.

[34] Q. Sun, Q.-Q. Ren, H. Li, Z.-W. Fu, High capacity Sb2O4 thin film electrodes for rechargeable sodium battery, Electrochem. Commun., 13 (2011) 1462-1464.

[35] D.Y.W. Yu, P.V. Prikhodchenko, C.W. Mason, S.K. Batabyal, J. Gun, S. Sladkevich, A.G. Medvedev, O. Lev, High-capacity antimony sulphide nanoparticle-decorated graphene composite as anode for sodium-ion batteries, Nat Commun, 4 (2013).

[36] L. Ji, M. Gu, Y. Shao, X. Li, M.H. Engelhard, B.W. Arey, W. Wang, Z. Nie, J. Xiao, C. Wang, J.-G. Zhang, J. Liu, Controlling SEI Formation on SnSb-Porous Carbon Nanofibers for Improved Na Ion Storage, Adv. Mater., 26 (2014) 2901-2908.

[37] S. Komaba, T. Ishikawa, N. Yabuuchi, W. Murata, A. Ito, Y. Ohsawa, Fluorinated Ethylene Carbonate as Electrolyte Additive for Rechargeable Na Batteries, Acs Appl. 
Mater. Interfaces, 3 (2011) 4165-4168.

[38] L.W. Ji, M. Gu, Y.Y. Shao, X.L. Li, M.H. Engelhard, B.W. Arey, W. Wang, Z.M. Nie, J. Xiao, C.M. Wang, J.G. Zhang, J. Liu, Controlling SEI Formation on SnSb-Porous Carbon Nanofibers for Improved Na Ion Storage, Adv. Mater., 26 (2014) 2901-2908.

[39] L. Bodenes, A. Darwiche, L. Monconduit, H. Martinez, The Solid Electrolyte Interphase a key parameter of the high performance of $\mathrm{Sb}$ in sodium-ion batteries: Comparative X-ray Photoelectron Spectroscopy study of $\mathrm{Sb} / \mathrm{Na}$-ion and $\mathrm{Sb} / \mathrm{Li}$-ion batteries, J. Power Sources, 273 (2015) 14-24.

[40] O.E.L. Perez, M.D. Sanchez, M.L. Teijelo, Characterization of growth of anodic antimony oxide films by ellipsometry and XPS, J. Electroanal. Chem., 645 (2010) $143-148$. 


\section{Figure Captions:}

Figure 1. (a) SEM image of the SiC-Sb-C composite; (b) XRD patterns of the $\mathrm{SiC}-\mathrm{Sb}-\mathrm{C}$ composite, pure $\mathrm{Sb}$ and $\mathrm{SiC}$ nanoparticles.

Figure 2. The initial two discharge/charge profiles of the $\mathrm{SiC}-\mathrm{Sb}-\mathrm{C}$ composite between $0.01 \mathrm{~V}$ and $2.0 \mathrm{~V}$ vs. $\mathrm{Na}^{+} / \mathrm{Na}$ at a current rate of $100 \mathrm{~mA} \mathrm{~g}^{-1}$ in FEC-free (a) and FEC-containing (b) electrolytes.

Figure 3. Cycling performance of the the $\mathrm{SiC}-\mathrm{Sb}-\mathrm{C}$ electrode at a cycling rate of 100 $\mathrm{mA} \mathrm{g}^{-1}$ in FEC-free and FEC-containing electrolytes.

Figure 4. Initial three cyclic voltammogram (CV) curves of the SiC-Sb-C electrode from $2.0 \mathrm{~V}$ to $0.01 \mathrm{~V}$ vs. $\mathrm{Na}^{+} / \mathrm{Na}$ at a scan rate of $0.1 \mathrm{mV} \mathrm{s}^{-1}$ without FEC (a) and with FEC (b) additive in the electrolyte.

Figure 5. The XPS C 1s (a), F 1s (b), Sb 3d (c) core peaks spectra of SiC-Sb-C composite electrode and FRIR spectra (d) of the SiC-Sb-C electrode before cycling and after 40 charge/discharge cycles at $100 \mathrm{~mA} \mathrm{~g}^{-1}$ in the FEC-free and FEC-containing electrolyte.

Figure 6. Electrochemical impedance spectra (EIS) of the SiC-Sb-C electrode at different discharge states in FEC-free and FEC-containing electrolyte.

Figure 7. Structural scheme of the film-forming mechanism of the SiC-Sb-C electrode in the FEC-free (a) and -containing electrolyte (b). 


\section{Table:}

Table 1. Simulation results of the EIS spectra using the equivalent circuit shown in Fig. 6.

\begin{tabular}{|c|c|c|c|c|}
\hline \multirow{2}{*}{$\begin{array}{c}\text { Discharge/charge } \\
\text { states }\end{array}$} & \multicolumn{2}{|c|}{ EC:DEC } & \multicolumn{2}{c|}{ EC:DEC:FEC } \\
\cline { 2 - 5 } & $\mathrm{R}_{\mathrm{SEI}}(\Omega)$ & $\mathrm{R}_{\mathrm{ct}}(\Omega)$ & $\mathrm{R}_{\mathrm{SEI}}(\Omega)$ & $\mathrm{R}_{\mathrm{ct}}(\Omega)$ \\
\hline D-2.0 V 2nd & 66.0 & 61.1 & 21.8 & 160.5 \\
\hline D-0.5 V 2nd & 664.4 & 729.5 & 48.4 & 190 \\
\hline D-0.2 V 2nd & 655.1 & 645.5 & 495.6 & 1301 \\
\hline
\end{tabular}



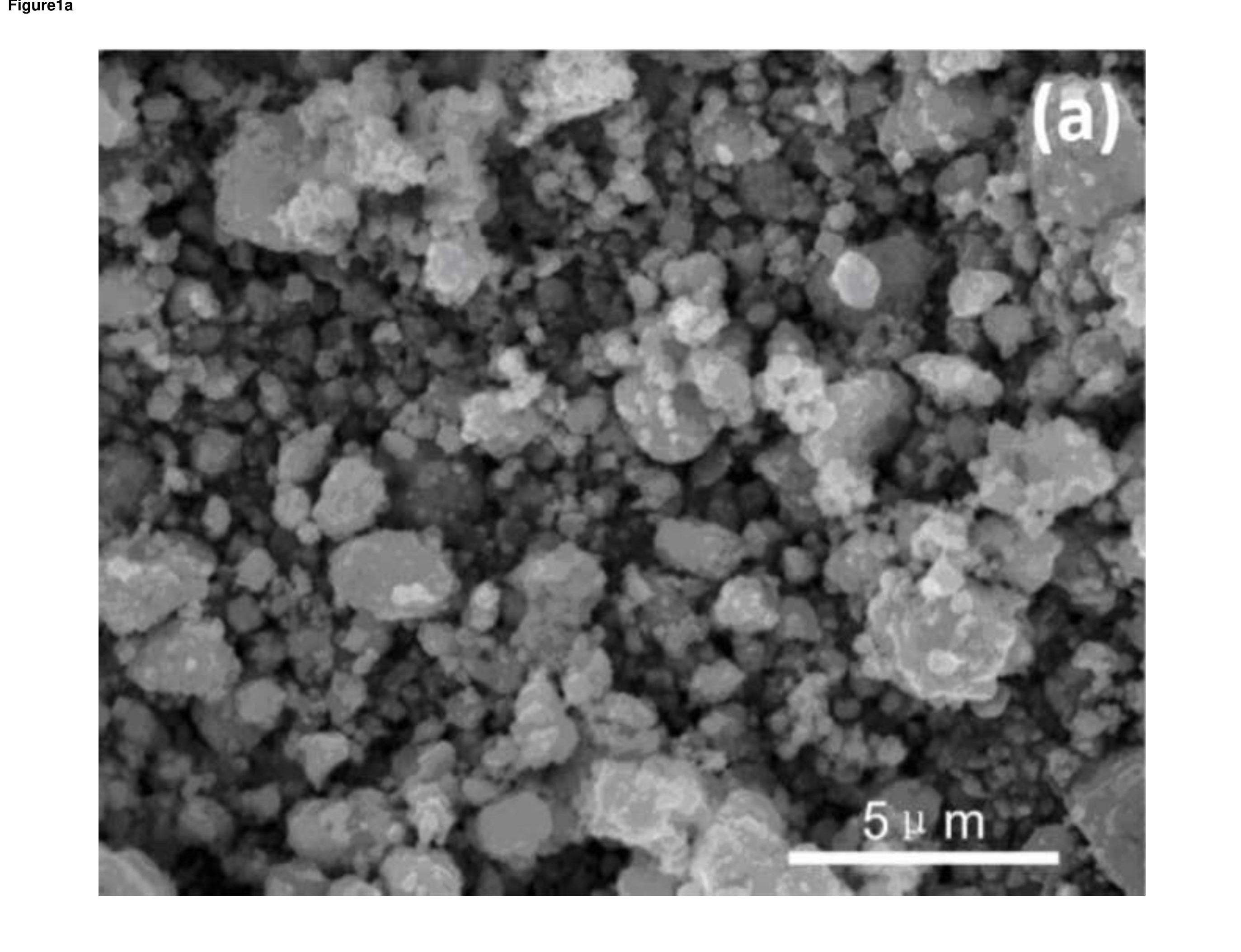
.
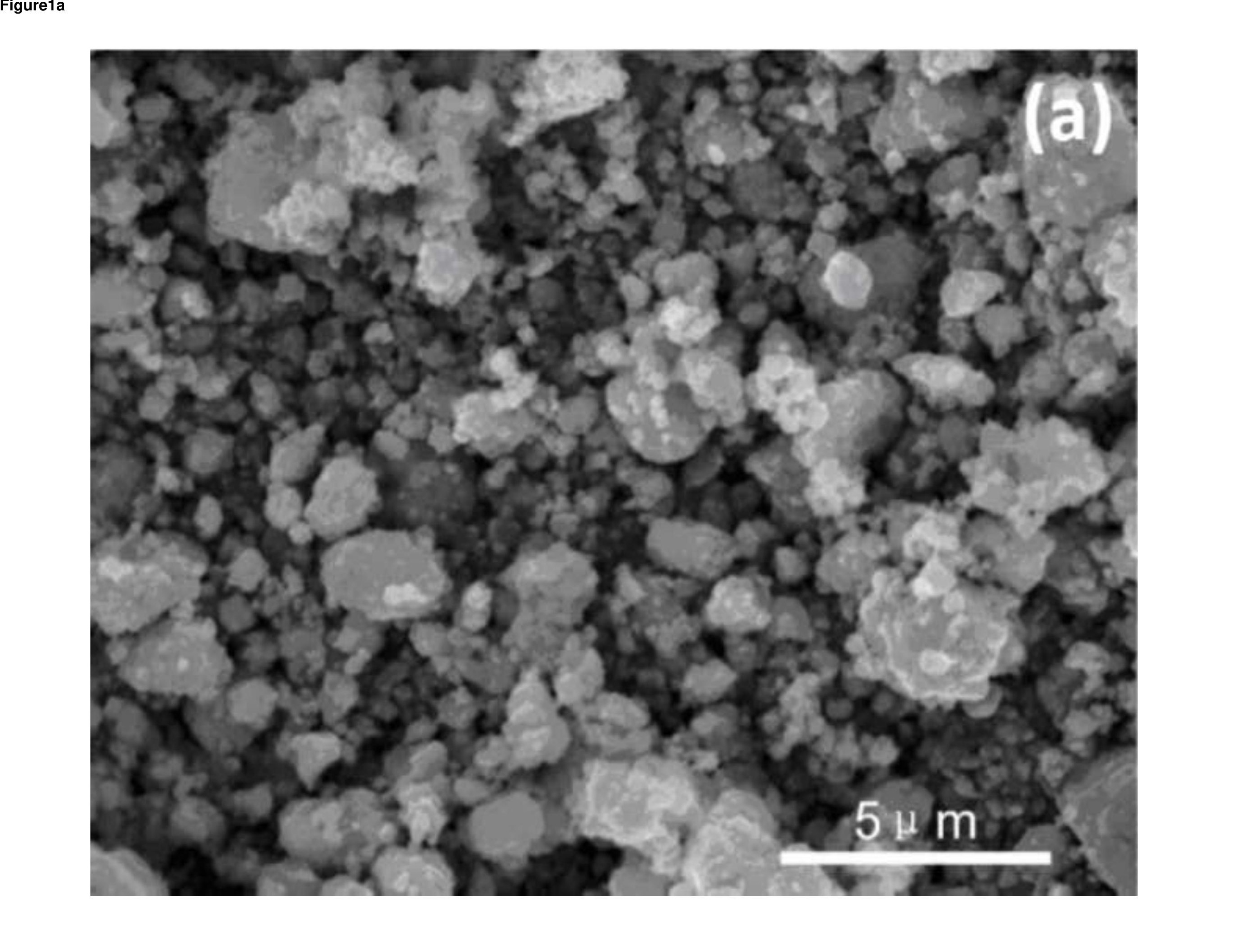


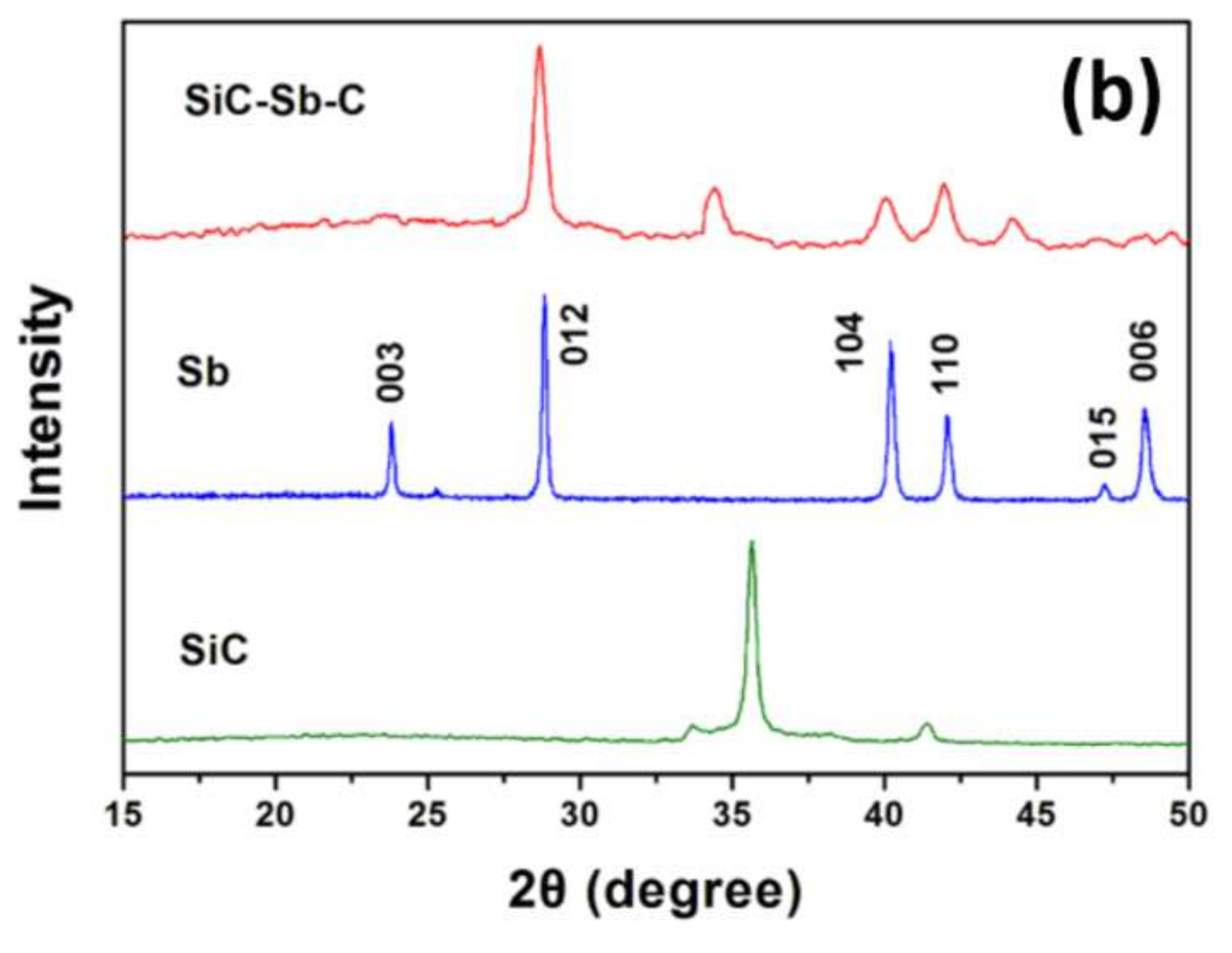

\begin{abstract}
.
\end{abstract}
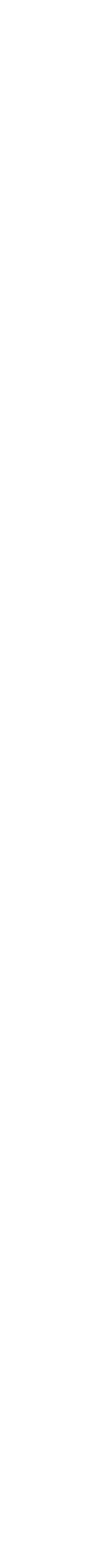


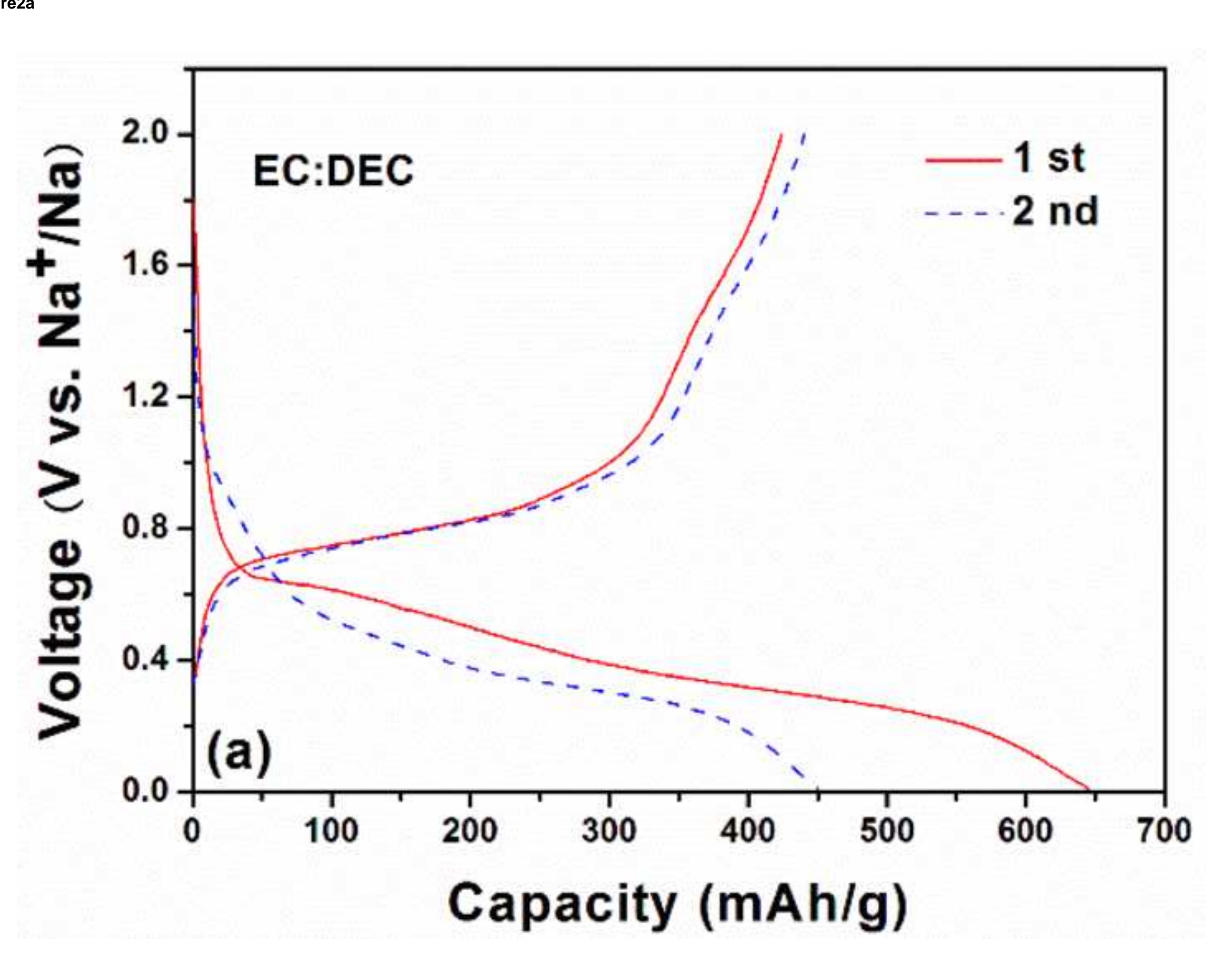
Fin
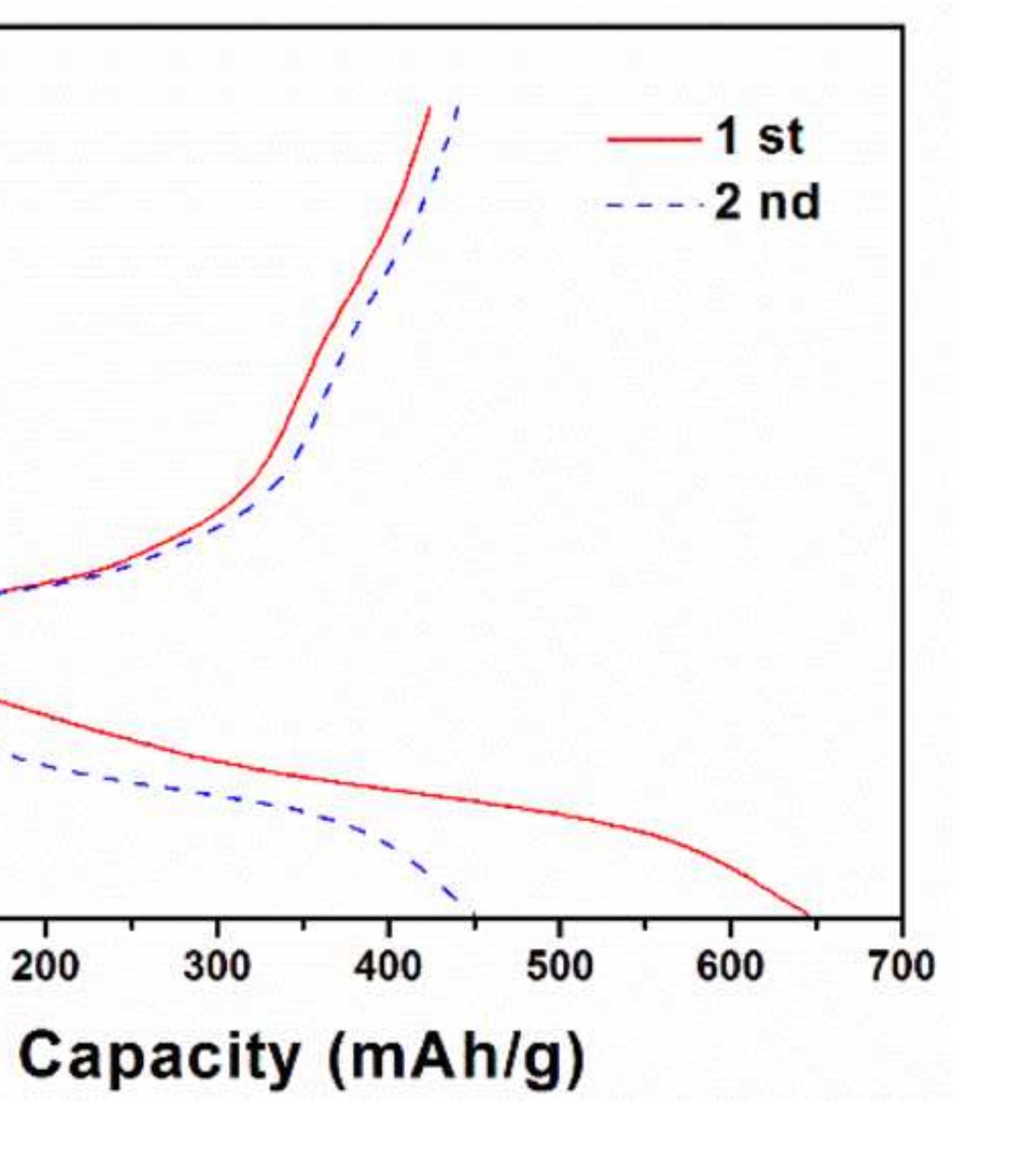


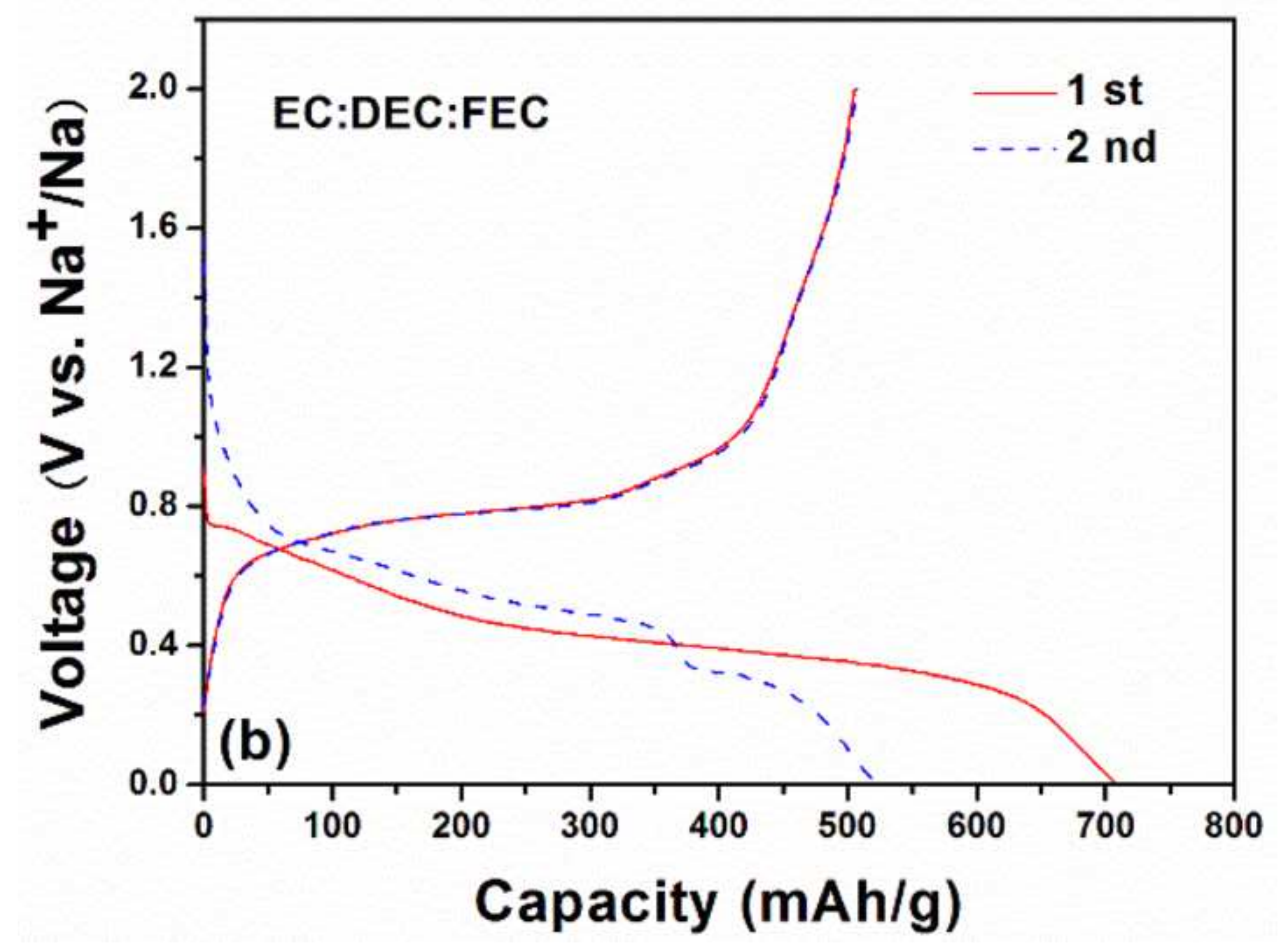
Figure

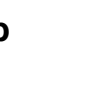

\footnotetext{
.
}

(

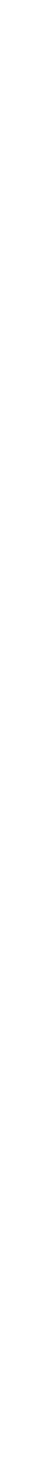



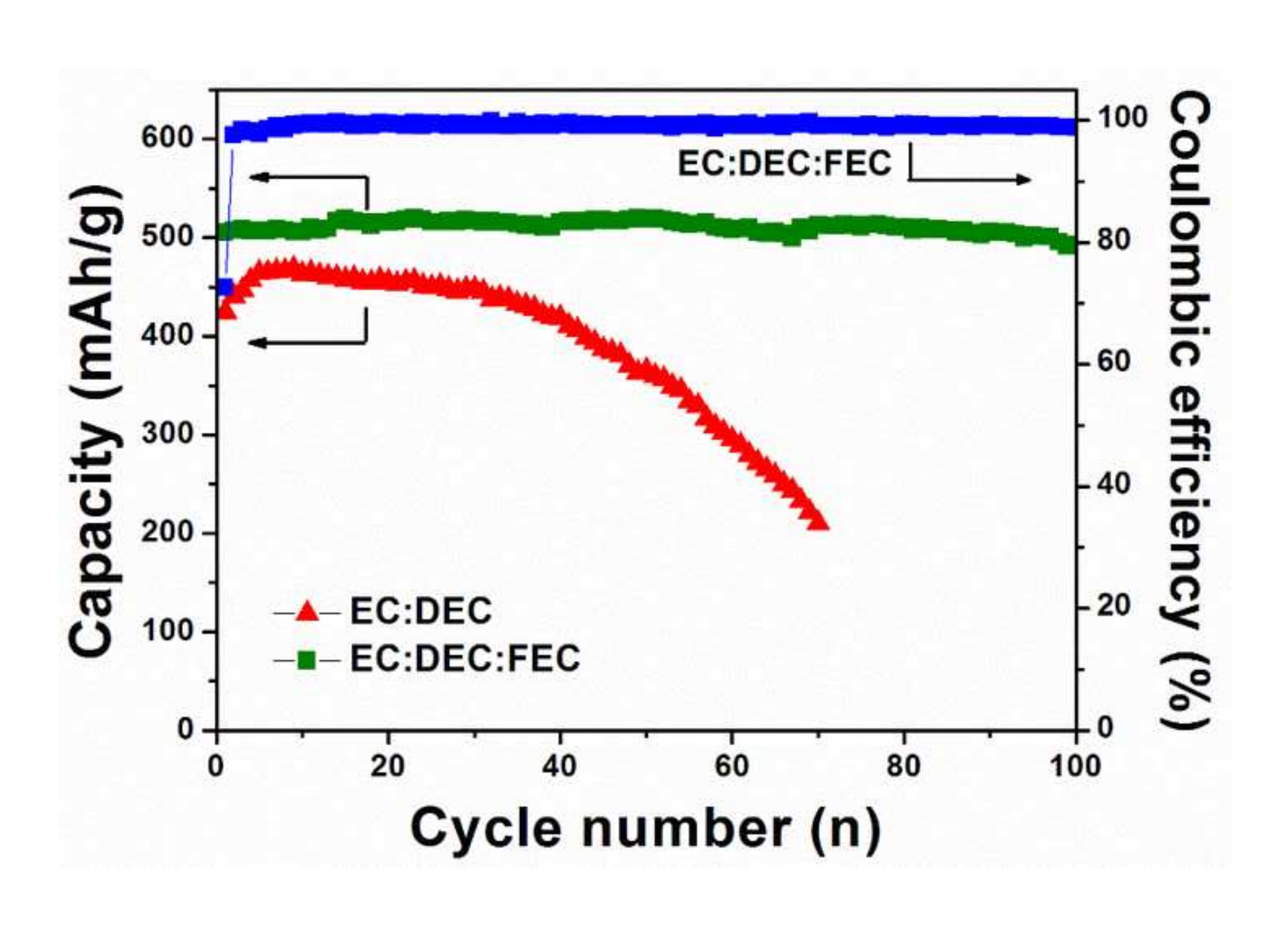



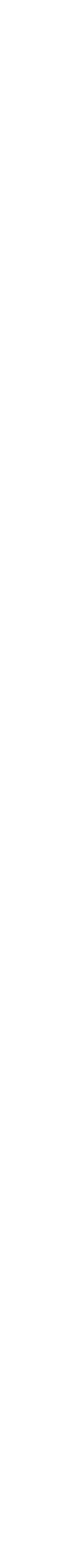

(I)




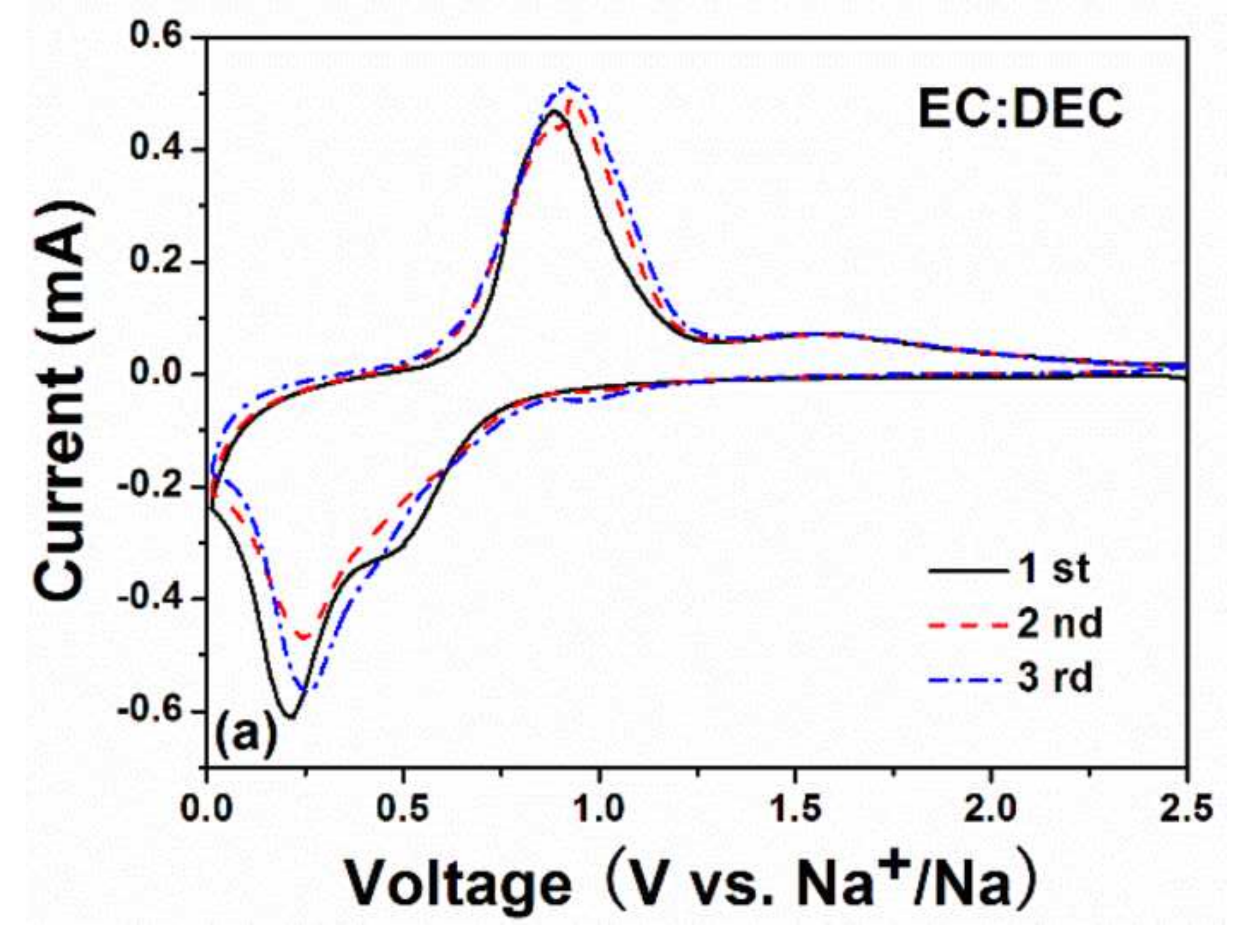



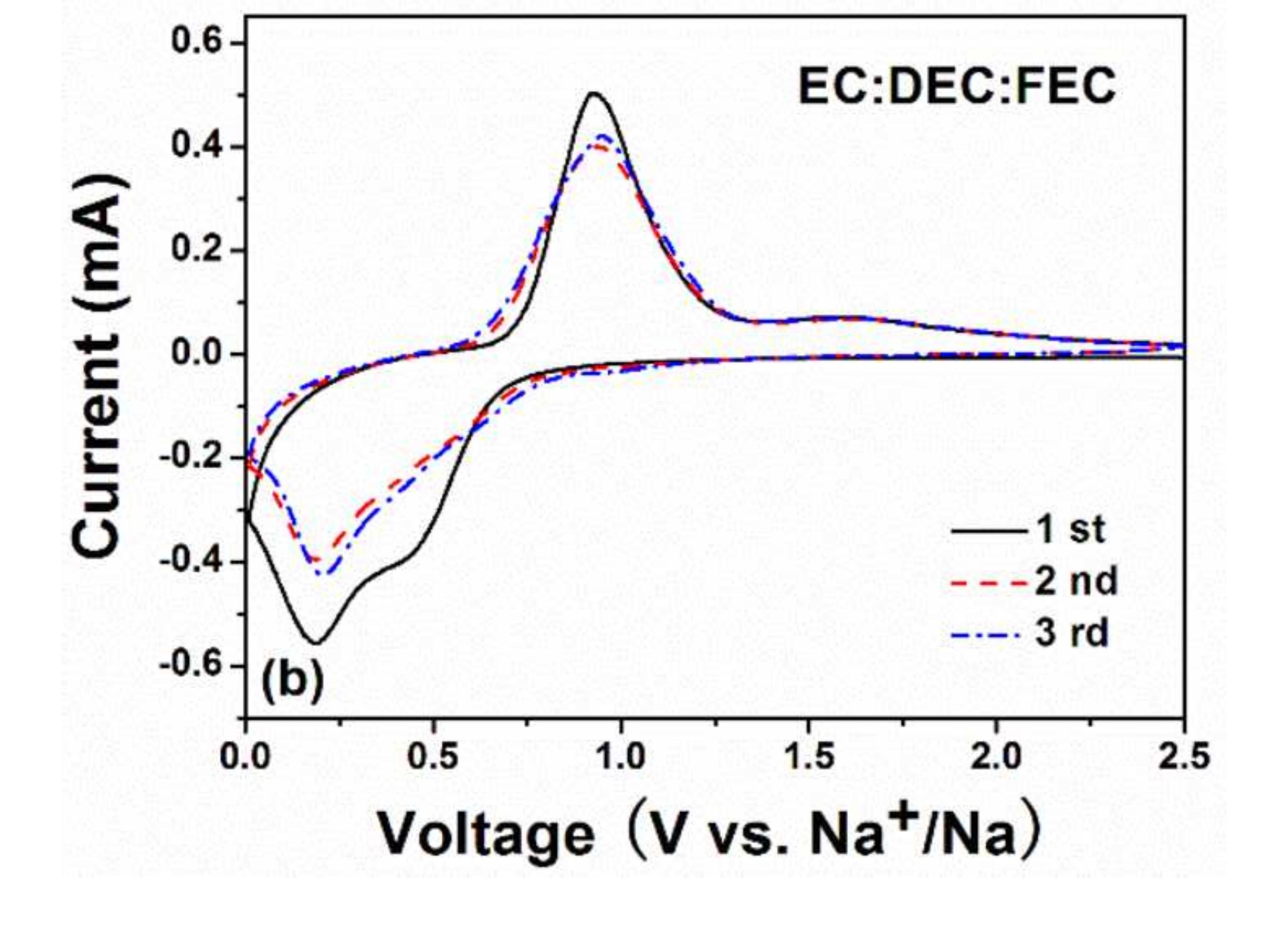


\section{0 th (EC:DEC:FEC)}

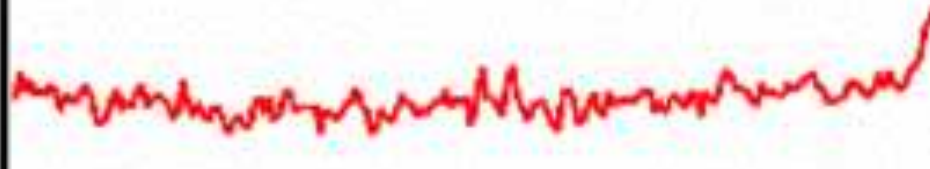

40 th (EC:DEC)

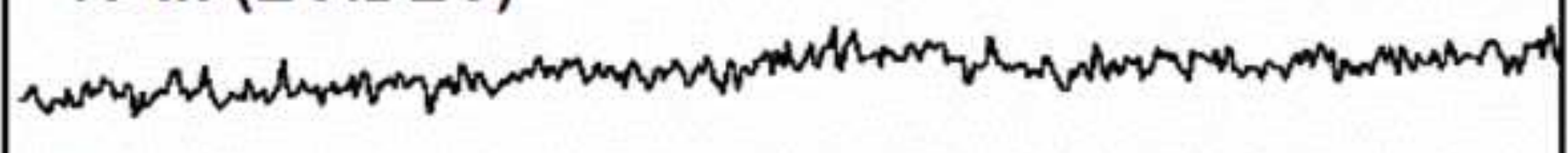

(b) 695

690

685

680

675

Binding Energy (eV) 


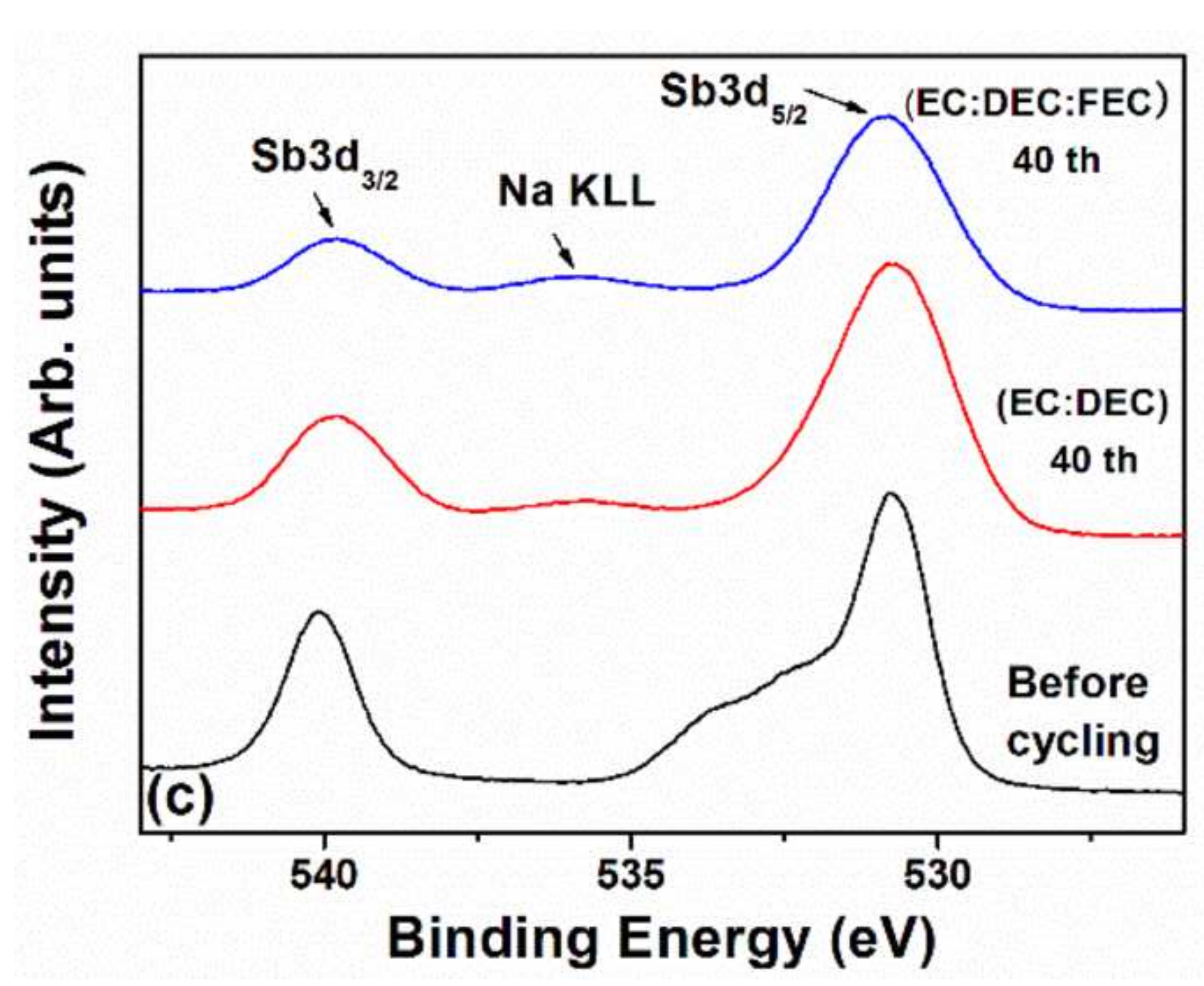




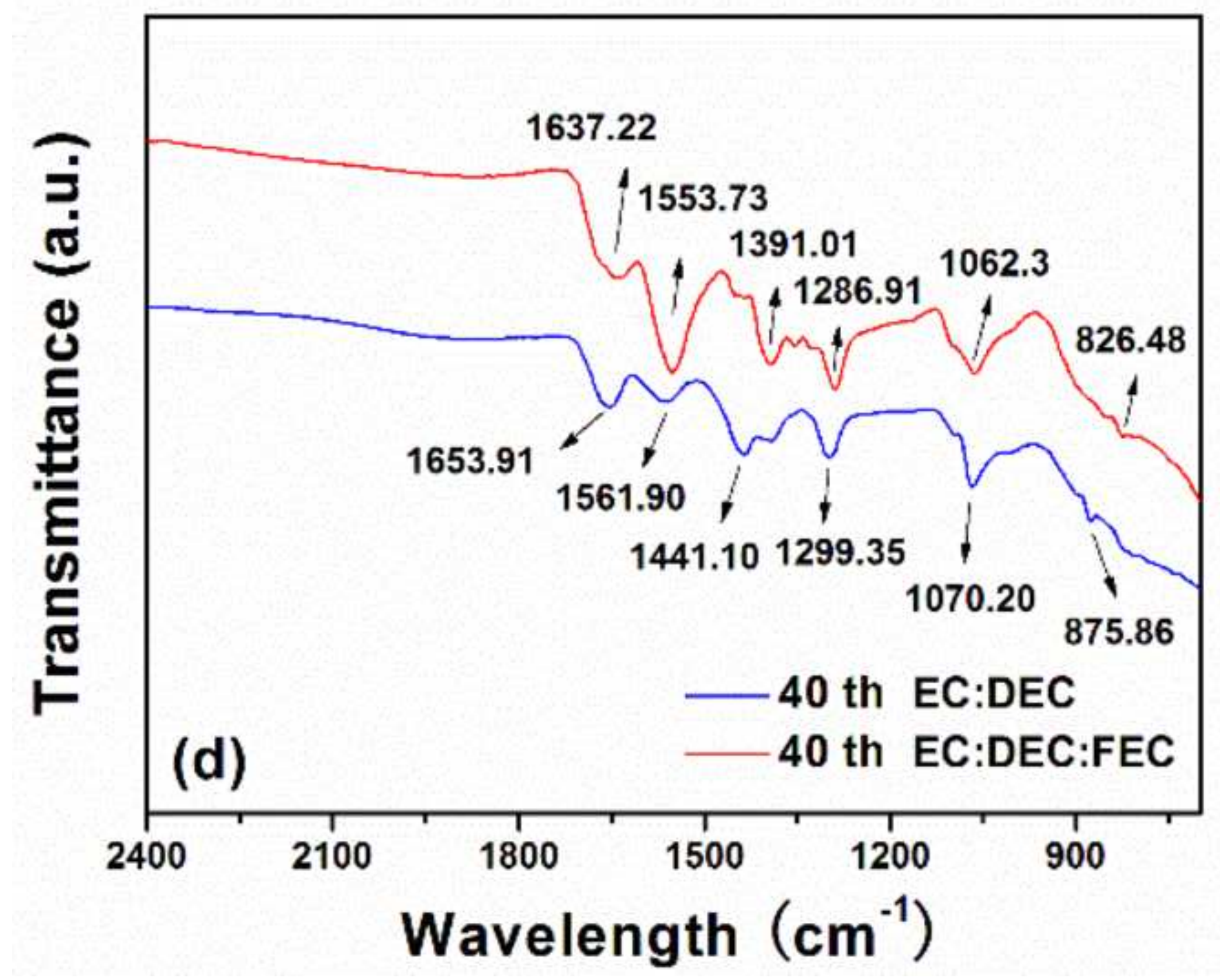




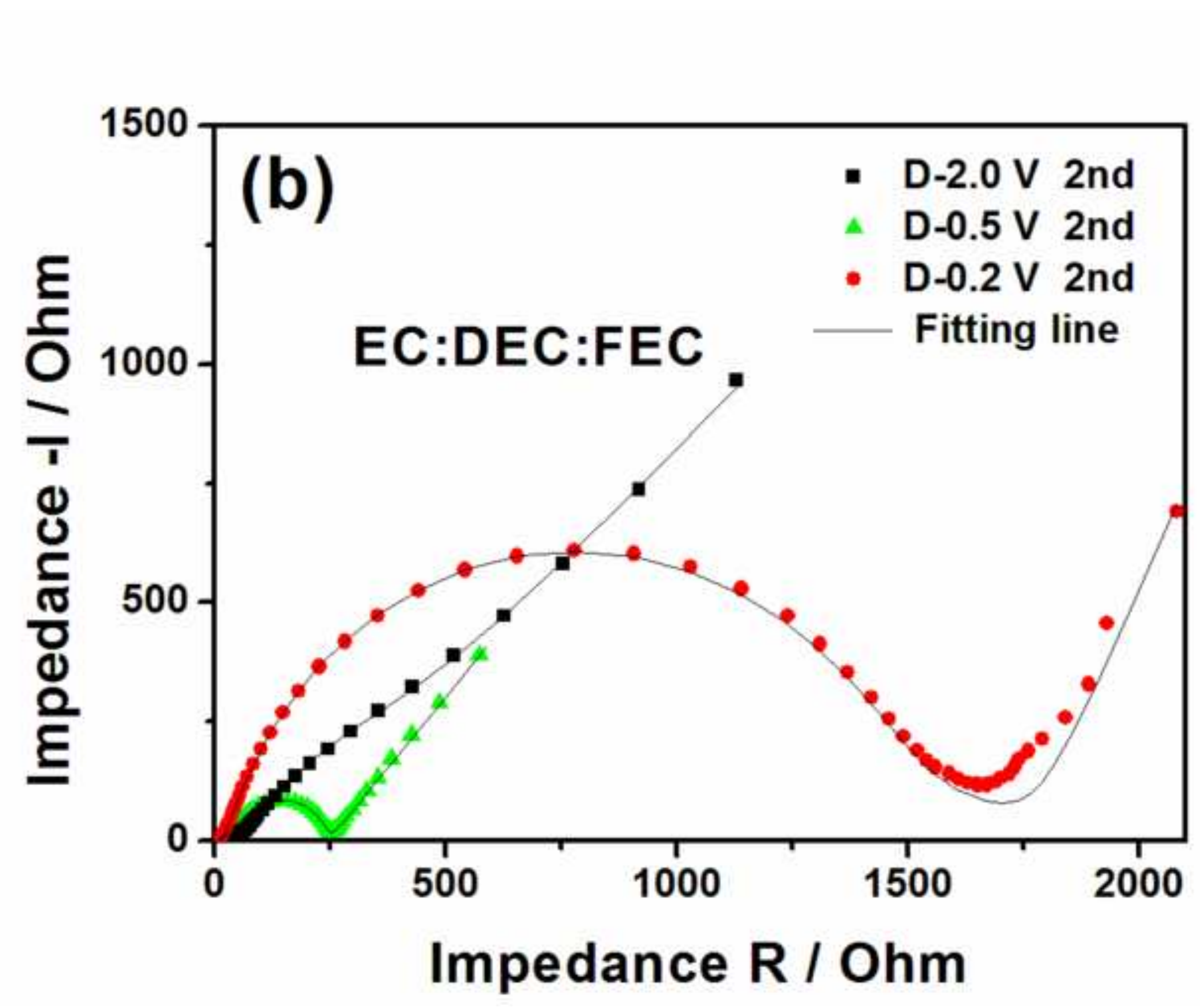




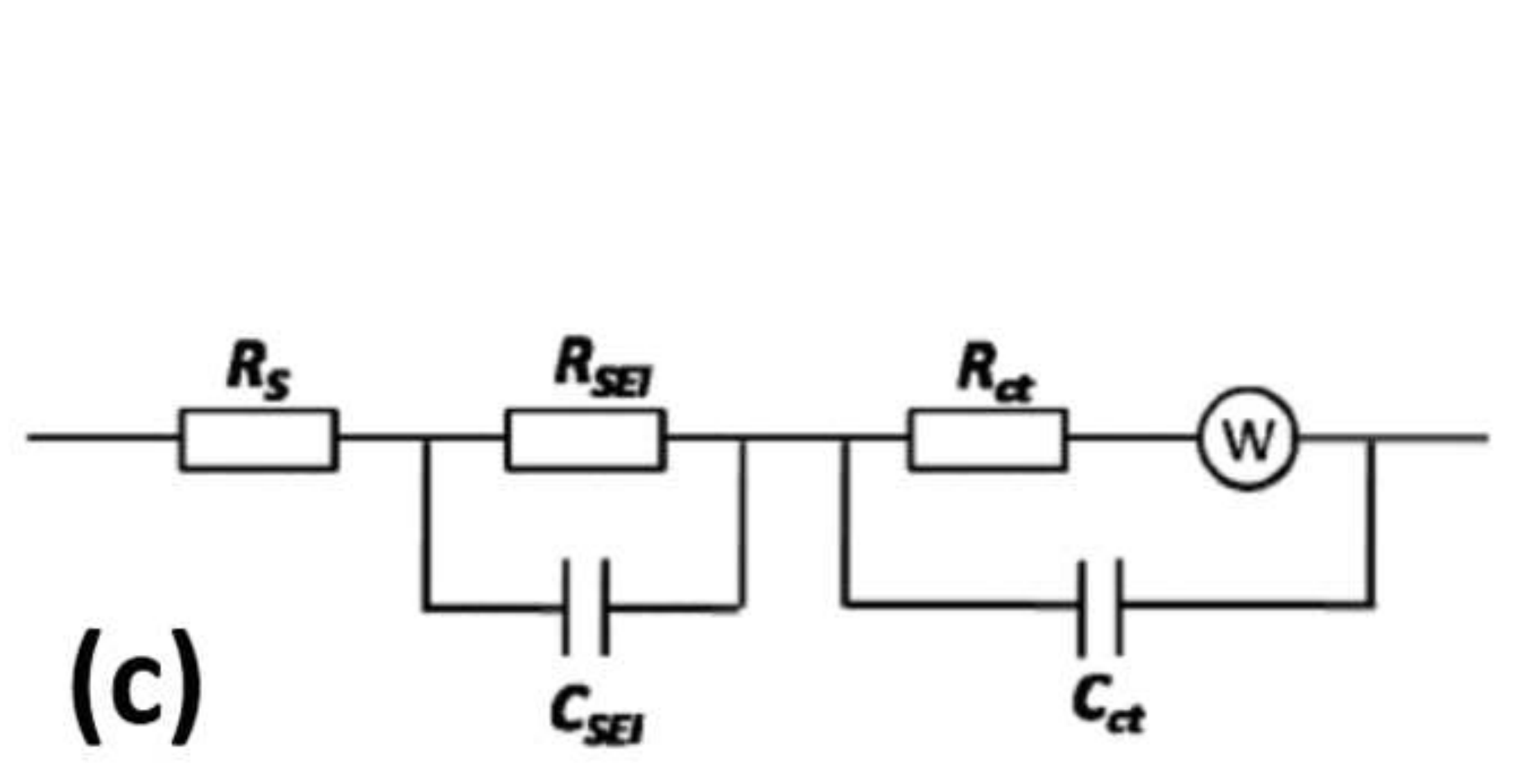

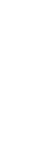
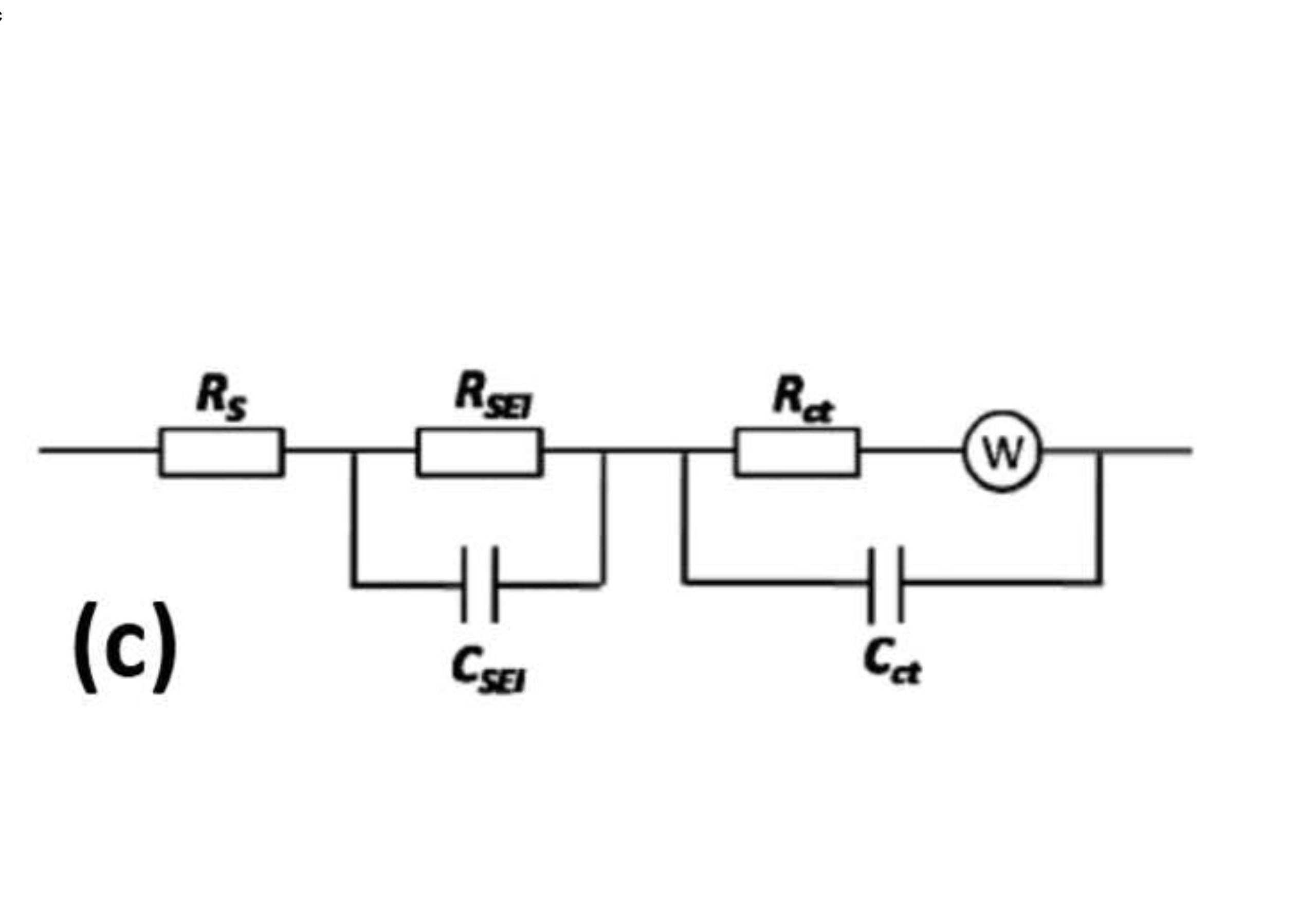
(a)

\section{EC:DEC}

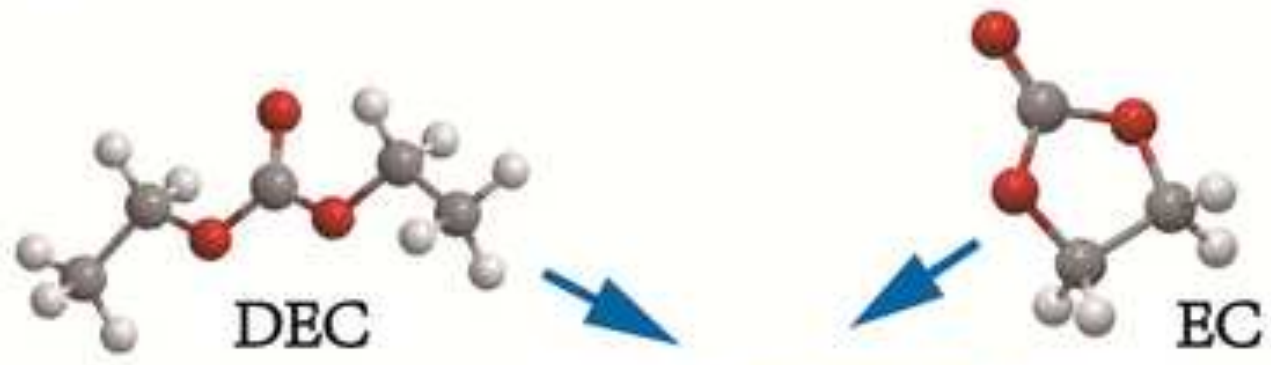

$\mathrm{Na}_{2} \mathrm{CO}_{3} \cdot \mathrm{ROCO}_{2} \mathrm{Na} \mathrm{RONa}$

$\mathrm{SiC}-\mathrm{Sb}-\mathrm{C}$

(b)

EC:DEC:FEC
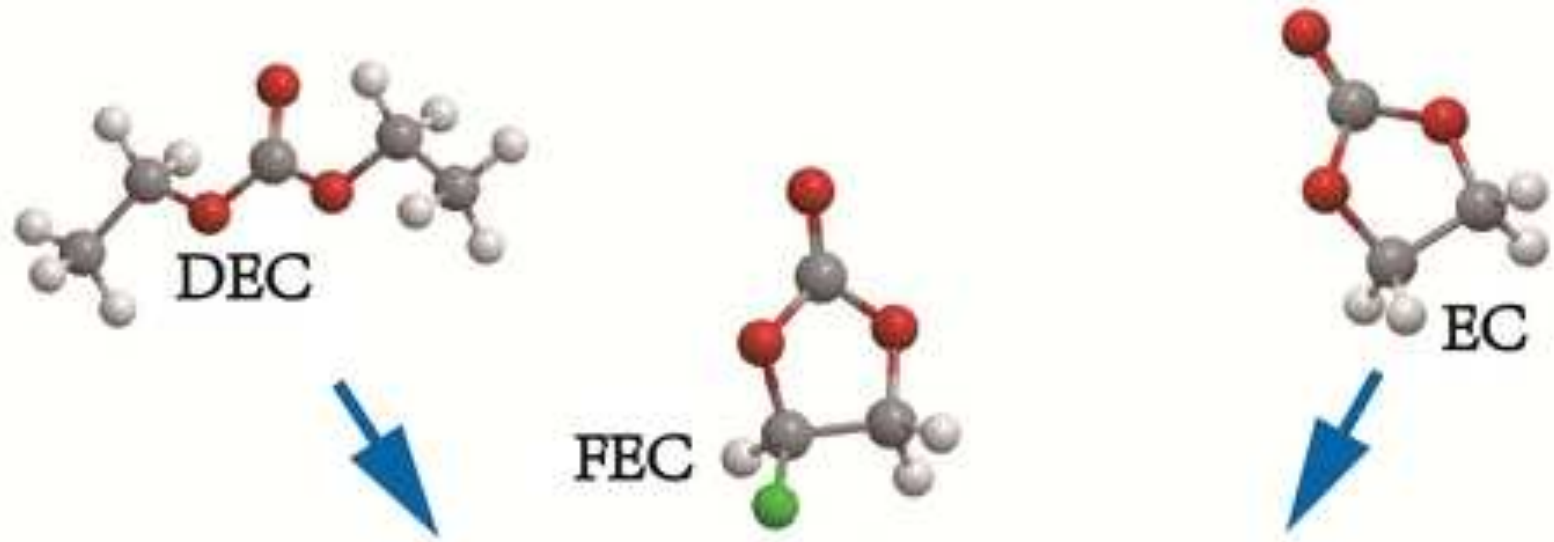

$\mathrm{Na}_{2} \mathrm{CO}_{3} \mathrm{ROCO}_{2} \mathrm{Na} \mathrm{RONa}$ NaF E-ROQO2Na E-RONars 


\section{Graphical Abstract}
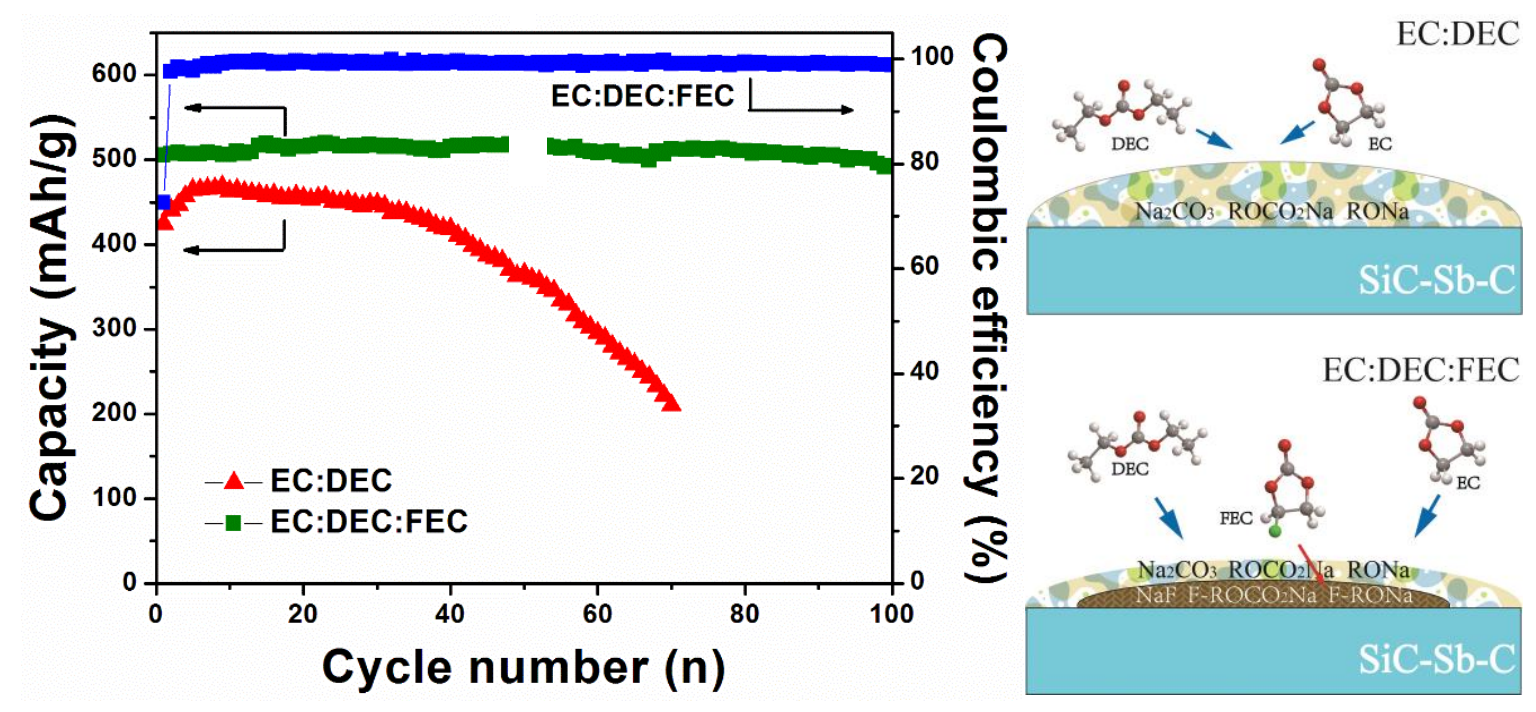

The effect of the FEC additive on the cycling stability of the Sb-based anode for Na-ion batteries was investigated. The introduction of FEC in the electrolyte can improve the cycling stability of the Sb-based anode, due to a double-layer SEI film formed on the electrode surface. 